\title{
Recepção da Antiguidade: a tirania de Pisístrato na defesa da monarquia moderada no jornal Correio da Liberdade (Porto Alegre, 1831)
} Reception of Antiquity: The Peisistratos'
Tyranny in the Defense of Moderate Monarchy in the
Correio da Liberdade Newspaper (Porto Alegre, 1831)

Anderson Zalewski Vargas*

\section{Resumo}

$\mathrm{O}$ artigo é resultado de pesquisa em andamento sobre a Recepção da Antiguidade por jornais gaúchos da primeira metade do século XIX e sobre a Retórica como ferramenta de análise textual. Analiso especificamente matérias do Correio da Liberdade, publicado em Porto Alegre, no ano de 1831. Em primeiro lugar, avalio alguns recursos retóricos clássicos utilizados para persuadir os leitores; em segundo, analiso a peculiar apropriação da tirania ateniense de Pisístrato em matéria sobre o regime político brasileiro da época, explicitando parte da corrente de recepções à qual ela pertence.

Palavras-chave: História da Recepção da Antiguidade no Brasil; retórica; tirania; História Antiga.

\section{Abstract}

This article is the result of research in progress conducted in connection with a project to study both the Reception of Antiquity by newspapers from the Brazilian South in the 19th century and the Rhetoric as textual analysis tool. I analyze specially articles of Correio da Liberdade, published in the city of Porto Alegre, Rio Grande do Sul, Brazil, in the year 1831. I firstly evaluate some classical rhetorical resources used to persuade the readers; secondly, I analyze the peculiar appropriation of the Athenian tyranny of Peisistratos in an article about the Brazilian political regime of that time revealing part of the chain of receptions to which it belongs.

Keywords: Reception History of Antiquity in Brazil; rhetoric; tyranny; Ancient History.

\footnotetext{
* Universidade Federal do Rio Grande do Sul (UFRGS), Porto Alegre, RS, Brasil. zalewski.vargas@ufrgs.br $<$ https://orcid.org/0000-0002-9516-6964>
} 
Meu objeto de análise neste artigo são algumas matérias do jornal Correio da Liberdade, editado em Porto Alegre: 75 números de 17 de abril a 31 de dezembro de $1831 .{ }^{1}$ Procuro conciliar História da Recepção com análise retórica, caminho não muito explorado no Brasil, mas apontado por Dominick LaCapra em artigo publicado originalmente em 1985, cuja frase inicial é: "O estudo da retórica está de novo na agenda dos estudos humanísticos” (LaCapra, 1996, p. 15). A cronologia particular do discreto interesse dos historiadores brasileiros pelo tema é evidenciada pela data da tradução do texto para o português (LaCapra, 2013). O que me interessa é que, ao distinguir três grandes orientações de estudos retóricos, LaCapra assevera ser a terceira, centrada em problemas de persuasão e audiência, capaz de converter a definição aristotélica de retórica em programa para uma estética da recepção (LaCapra, 1996, p. 17). À primeira vista, "recepção" - em português e inglês, ao menos - apresenta um marcado aspecto de passividade. Charles Martindale, incomodado, respondeu a isso defendendo o "poder de recepção" como um princípio cognitivo ativo (Martindale, 2013, p. 174). Sua fonte é Hans Robert Jauss, um dos teóricos-base da sua formulação de História da Recepção e dos estudos de recepção em geral (Hardwick, 2003, p. 7-9). Em artigo de 1977, o teórico da Estética da Recepção propôs o retorno a um antigo sentido do termo alemão para prazer (Geniessen): "ter o uso ou o proveito de uma coisa". Apenas na época do classicismo germânico, o significado latente de "participação e apropriação" e o sentido específico de "alegrar-se com algo" teriam se unido de forma peculiar (Jauss, 2002, p. 85).

O ponto que preciso destacar é a valorização do intérprete, do leitor, do receptor de um texto, imagem, escultura, filme... É o leitor que, do vasto conjunto de possibilidades a sua disposição, escolhe este ou aquele objeto e o pensa estabelecendo "cadeias de recepções" que podemos, com sorte, reconstruir. A noção de "cadeia de recepções" é de Hans Georg Gadamer; Martindale igualmente a sustenta, de forma recorrente, com um pequeno ensaio de T. S. Elliot, Tradição e talento individual (1919). Essas cadeias são estabelecidas pelos receptores conforme um conjunto de variáveis a ser determinado (formação intelectual, por exemplo). $\mathrm{O}$ resultado não pode ser avaliado pela sua pertinência a uma interpretação imanente daquilo que é apropriado. Por trás disso, está a tese de que nada carrega consigo o que deve ser pensado a seu respeito. É noção recebida da hermenêutica gadameriana: as interpretações são sempre realizadas na história e sujeitas às contingências do momento histórico - não há, para os humanos, posição análoga à da onisciência divina, a qual nos permitiria uma interpretação além da história (Martindale, 2007, p. 301). Nas 
contingências do "momento histórico" estão incluídas nossas crenças e preconceitos que, ao invés de obstáculos ao entendimento, são elementos constituidores de nosso pensamento (Gadamer, 1999, p. 416). No meu caso, a despeito de meu juízo sobre a pertinência da recepção da tirania ateniense contida na matéria que analiso, importa mais entender seus sentidos e implicações no contexto do século XIX e de hoje: o que ela pode nos revelar sobre a visão de um passado distante e seu uso para pensar os destinos da então nascente nação brasileira, a posição da Antiguidade na reflexão intelectual e política do redator de meus documentos.

Escrevi este artigo em decorrência de um projeto cuja pretensão é abarcar História da Recepção da Antiguidade e avaliar alternativas hermenêuticas da análise retórica, tendo por objeto de estudo a imprensa da quadra marcada pela Revolução Farroupilha (1835-1845). Esse evento, central à identidade dos habitantes de meu estado graças a um admirável trabalho criativo iniciado ainda no início do século passado (e acentuado a partir de 1935, quando foram realizadas as festividades de seu centenário), foi um dos vários que abalaram o período anterior à maioridade do segundo imperador brasileiro.

A pesquisa de arquivo, em parte concluída, contou com apoio do $\mathrm{CNPq}$ e da Propesq/UFRGS e, no caso desse jornal, devo muito ao trabalho do hoje professor Rafael Santos de Abreu. O início do título de seu Trabalho de Conclusão de Curso (TCC) é evidência conhecida da presença, até o momento praticamente ignorada pelos investigadores, da invocação da Antiguidade na história sul-rio-grandense: "Sejamos gregos na glória / e na virtude, romanos". Antes do regime instaurado pelo golpe de 1964, havia uma estrofe acrescida à terceira versão do hino da República instaurada pelo movimento de 35:

Entre nós reviva Atenas

Para assombro dos tiranos;

Sejamos gregos na Glória,

E na virtude, romanos.

É possível que os dois primeiros versos tenham sido a razão de embaraço, de temor e da consequente exclusão da estrofe pela Lei 5.213 de 1966, que dispunha sobre a forma e a apresentação dos símbolos do estado do Rio Grande do Sul. ${ }^{2} \mathrm{O}$ responsável pela exclusão, Getúlio Marcantonio, deputado à época, disse, recentemente, que ninguém cantava aquela parte, referente "a povos sem identificação com o povo gaúcho”. Uma tentativa de reinserir a passagem foi arquivada em 2007, com o que concordou o então presidente do 
Movimento Tradicionalista Gaúcho, Manoelito Savaris: "Um povo tem de contar a si mesmo em seu hino. Fui contra quando quiseram reincorporar" (Costa, 2015). O estudo dos jornais do século XIX mostra exatamente o contrário: os gaúchos e os brasileiros de então tinham relação estreita com o passado greco-romano.

Trato sucintamente de dois aspectos do Correio da Liberdade. O primeiro, concernente a uma estratégia retórica específica, na relação do editor com o leitor, no prospecto do jornal. O segundo, relacionado à persuasão dos assinantes e eventuais leitores, em matéria sobre tema candente do Brasil daquela época: a monarquia brasileira deveria ser absoluta ou constitucional? Esse documento despertou minha atenção por invocar a tirania ateniense de Pisístrato para defender a opção constitucional. Para quem não é especialista em História Grega Antiga, esclareço ter sido Pisístrato um tirano ateniense no século VI antes de nossa era, e que os tiranos helenos foram, em geral, aristocratas que monopolizaram o poder e governaram acima das instituições de suas póleis. A tirania, em termos gerais, pode designar: "a usurpação do governo da pólis por um indivíduo, mas por si só não era uma forma específica de constituição" (Ehrenberg, 1960, p. 45). ${ }^{3}$ As duas matérias analisadas são evidência da vitalidade da retórica e da Antiguidade não apenas no jornalismo brasileiro do século XIX, mas na reflexão política cotidiana daquela época sobre os tempos que corriam.

\section{CONSIDERAÇÕES PRELIMINARES}

Como mencionado, este artigo é resultante de projeto de pesquisa cuja pretensão inclui a investigação teórico-metodológica da retórica, principalmente avaliando as suas alternativas hermenêuticas para análise histórica de textos. Nesse sentido, uma útil contribuição pode ser considerada a partir desta passagem de Quintiliano sobre argumentos: "Passo agora àqueles assuntos com os quais trabalho e que se referem diretamente às pessoas e por isso devem ser tratados em primeiro lugar. Daqui para diante, em tudo o que se fizer, pergunta-se ou Por quê? Ou Onde? ou Quando? ou Como? ou Com que meios? foi feito" (Quintiliano, Instituição Oratória, V. 10, 32).

Aparentemente, Olivier Reboul, em sua Introdução à Retórica (Reboul, 1998, p. 140-143), fez dessas proposições um programa de "leitura retórica", apresentando estas perguntas como "lugares da interpretação" de um texto e de seu formulador: Quem é o autor? Quando foi escrito? Contra o que se escreveu? Por que se escreveu? Como foi escrito? Para quem foi escrito? Acrescente-se 
a isso a preocupação com gênero do escrito, algo que em história corresponde à investigação sobre a natureza das fontes, mas com atenção para as características dos gêneros de textos.

Avaliando retrospectivamente seu caminho de pesquisa, Cláudio Pereira Elmir definiu dois gêneros de apropriação de tal resquício do passado na perspectiva da sua recepção por pesquisadores:

O jornal, nesta perspectiva da recepção, pode ser apropriado das mais diversas formas. [...]. Uma delas, aparentemente mais simples, consiste em tomá-lo (1) como fonte de informação. A segunda delas, aparentemente mais complexa, faz dele (2) objeto intelectual da pesquisa. [...] Se o jornal se transforma, para o pesquisador, em objeto intelectual, as perguntas feitas a ele alteram-se, até certo ponto. Paradoxalmente, elas demandam uma operação paralela e oscilante pela qual expulsam o pesquisador para fora do texto e, ao mesmo tempo, o empurram para dentro. (Elmir, 2012, p. 78-80)

Este texto se insere na segunda alternativa indicada: o jornal como um objeto intelectual e não como simples crônica dos tempos, a exigir relações com o contexto de seu tempo e com os indicados pelo próprio documento, como as "cadeias de recepções" da Antiguidade. É proposição semelhante àquela feita por Dominick LaCapra ao tratar da História Intelectual de textos "complexos", dos "grandes textos da tradição ocidental" (LaCapra, 1998, p. 239). O historiador norte-americano distingue um caráter documentário - o qual "situa o texto em termos de dimensões fáticas ou literais que implicam a referência à realidade empírica e transmitem informação sobre ela" - e outro, baseado nas ideias de Martin Heidegger, como "ser - obra", o qual "complementa a realidade empírica com agregados e subtrações" (LaCapra, 1998, p. $245,267)$.

Os primeiros jornais brasileiros - editados a partir da transferência da família real portuguesa do Rio de Janeiro em 1808 - sempre apresentaram preponderância de artigos políticos, reflexivos e voltados para ação direta. Os estudos de Isabel Lustosa, entre outros, mostram como estiveram diretamente envolvidos na independência brasileira. Insultos Impressos, que tem como marco temporal os anos de 1821 a 1823, demonstra a intensa participação da imprensa no debate sobre a definição do formato político da nação brasileira (Lustosa, 2000, p. 26). A efervescência da discussão política persistiu com a abdicação de Pedro I, quando a polêmica sobre a natureza do poder central dominou as páginas dos periódicos jornalísticos nacionais. Como observou 
José Murilo de Carvalho: “Até o início do Segundo Reinado, o debate político concentrava-se na imprensa e na Tribuna do Parlamento" (Carvalho, 2007, p. 19) Essa situação também ocorreu no Rio Grande do Sul até as primeiras décadas do século XX.

O surgimento da imprensa no Rio Grande do Sul, como no resto do país, esteve ligado às lutas políticas que caracterizaram o processo de construção do Estado nacional brasileiro. No caso gaúcho, também esteve vinculado aos acontecimentos que levaram à Revolução Farroupilha, movimento que ameaçou o processo de centralização política então em curso. Foi no clima de efervescência política que antecedeu e acompanhou aquela sublevação que surgiu uma série de pequenos e efêmeros jornais ligados aos partidos em luta. $O$ Diário de Porto Alegre, por exemplo, originou-se da iniciativa do presidente da província, Salvador José Maciel, que, preocupado com a difusão de ideias ameaçadoras à estabilidade de sua autoridade, tratou de patrocinar um órgão que publicasse atos da administração e fizesse a publicidade de seu governo (Rüdiger, 1990, p. 10-11).

De 1827 a 1845, uma "febre de pequenos jornais políticos" se espalhou pela província. Não teria existido no período um único jornal que não estivesse filiado aos partidos existentes ou a um elemento importante das duas facções políticas da província: legalistas e farroupilhas (Baumgartem, 1982, p. 24). Com poucas notícias e anúncios, esses periódicos eram instrumento dos interesses das correntes políticas, veiculando matérias opinativas de cunho político-doutrinário.

Essa característica torna os periódicos jornalísticos ainda mais afeitos ao segundo tipo de investigação histórica definida por Cláudio Elmir. Em resumo: estou interessado em analisar a imprensa com um texto complexo, considerando aquilo que ela acrescentou ao seu tempo por meio de matérias reflexivas sobre o destino político-constitucional do país em que a Antiguidade desempenhou papel central. Em razão da compartimentação dos estudos históricos, a invocação argumentativa do Mundo Antigo tem passado despercebida pelos colegas de História do Brasil, e sua simples apresentação pode surpreender a muitos.

\section{O CORREIO DA LIBERDADE: OS ANTIGOS}

E ALGUMAS ESTRATÉGIAS RETÓRICAS

Há um bom número de estudos a esclarecer a qualidade retórica da produção intelectual dos períodos colonial e imperial. Inicialmente, pela ação de 
jesuítas, e, com a expulsão desses, prosseguida pela reforma do ensino português dirigida pelo marquês de Pombal. No Rio de Janeiro, antes mesmo de $O$ Verdadeiro Método de Estudar, de Luís António Verney (1746), e das Lições Elementares de Eloquência Nacional para uso da mocidade de ambos os hemisférios, de Francisco Freire de Carvalho (1834), a eloquência lusófona já era difundida por diversos outros textos e pelas orações dos púlpitos das igrejas (Duran, 2013, p. 175). De acordo com a obra de Roberto Acízelo de Souza, O Império da Eloquência, o estudo da retórica foi hegemônico na formação intelectual dos brasileiros até o início do século XX (Souza, 1999, p. 36). Fernando de Araújo Penna, em "A importância da tradição clássica no nascimento da disciplina História no Imperial Colégio de Pedro II”, também oferece importante indício para compreendermos a recorrente invocação da Antiguidade no debate político e na produção intelectual brasileira do XIX. Desde 1837, ano da criação daquela instituição, "a erudição ligada à tradição clássica permeava todo o currículo", além da presença evidente em disciplinas específicas como Latim, Grego, Religião e História Sagrada, Retórica (Penna, 2008, p. 72). Até a consolidação do Instituto Histórico e Geográfico Brasileiro (fundado em 1838), a Antiguidade dominou os conteúdos da disciplina de História. Dataria da década de 1870 o início do recuo da erudição clássica (Penna, 2008, p. 73-76).

A despeito de isso ser evidente hoje, o marco da multiplicação de estudos sobre a dimensão retórica da educação brasileira até o início do século XX é um artigo de 2000, de José Murilo de Carvalho: "História intelectual no Brasil: a retórica como chave de leitura". Nesse importante artigo, é referida a conspícua citação de autores antigos e de suas obras (Carvalho, 2000, p. 142). Como pondera, pode se tratar de argumento de autoridade e mesmo de um vício de linguagem, explicado pela ausência de prática científica (p. 145). Em minha opinião, as matérias analisadas nesse artigo revelam as particularidades de uma época em que a formação intelectual não prescindia da tradição greco-romana e mesmo bíblica, e o passado mais distante era concebido de tal forma que podia sustentar a reflexão sobre o presente e o futuro político do país.

As edições do Correio da Liberdade eram impressas em tipografia própria, primeiramente na rua de Bragança, 5, e logo depois na rua do Cotovelo, 26 (Klafke, 2011, p. 35). As publicações ocorriam às quartas-feiras e aos sábados, em folha dupla (quatro páginas), no formato de $22 \times 32 \mathrm{~cm}$, um pouco maior que o formato A4 com o qual estamos sobejamente familiarizados. 
A assinatura custava 4.000 réis por semestre, e o exemplar avulso era vendido a 80 réis, preços quase que padronizados para os jornais do período. Também seguindo o costume da época, a subscrição foi lançada antes da publicação, por meio de um prospecto no qual era anunciado que "logo que houver suficiente número de assinantes, publicar-se-á nesta cidade de Porto Alegre o Periódico intitulado Correio da Liberdade". (Abreu, 2014, p. 22)

O proprietário era também editor, o rio-grandino Manoel dos Passos e Figueiroa, posteriormente responsável por outras duas folhas: A Idade D’Ouro (1833) e O Analista (1844). Sua alcunha era Calcas (Abreu, 2014, p. 23), nada mais nada menos que o principal adivinho da Ilíada - provavelmente, Manoel pretendia que fossem associadas a si as qualidades do "melhor dos adivinhos", cujos vaticínios guiaram os aqueus a Troia: "Todas as coisas ele sabia: as que são, as que serão e as que já se foram" (Homero, Ilíada, I, 69-70). Como o público para quem se dirigia era o de uma minoria de formação intelectual, podemos supor que a analogia tivesse boas chances de ser feita pelos leitores.

Um conhecimento da filosofia política latina poderia ser inferido da epígrafe que encimou todas as edições do Correio: "Unum debet esse omnibus propositum, ut eadem sit utililas uniuscujusque et universorum (Cic. de Off. Lib. I)". "[Portanto], deve haver em todos o propósito único de fazer com que o interesse de cada um coincida com o interesse geral" compõe sentença do livro III (VI, 26) de Dos Deveres, de Cícero. ${ }^{4}$ Álvaro Klafke especula que o uso dessa epígrafe sem tradução visasse estabelecer vínculos com a "boa sociedade" do campo politicamente moderado (Klafke, 2011, p. 38) Em termos retóricos, podemos pensar o papel da epígrafe na conformação de um éthos persuasivo, a pretensão de constituir uma prova ética. Em sua Retórica, Aristóteles a alinhou às provas passional (páthos) e lógica (lógos), mas considerou o éthos como o mais relevante elemento persuasivo, pois seria através da transmissão, pelo discurso, de um caráter pessoal digno de fé que melhor persuadiríamos terceiros (Aristóteles, Retórica, I 1356a 1-13). ${ }^{5}$

O caráter politicamente moderado é evidente no Prospecto, edição de uma página que buscava obter financiamento prévio para viabilizar a publicação. Ao justificar o nome da folha, o primeiro argumento é a apresentação das suas finalidades: "illustrar nossos Patrícios nos princípios constitucionais, por que se devem guiar" $\mathrm{e}$ informar sobre "os negócios mais interessantes a esta província”. Também seriam publicados atos do governo, haveria transcrições dos "Periódicos Nacionais livres", daquilo que fosse "mais acomodado" aos seus "interesses peculiares". O que seria a imprensa "livre"? Pelo que está escrito na sequência, 
seria aquela que, por um lado, não publicasse material que fosse "de encontro ao Systema Constitucional" ou que perturbasse o "socego público"; por outro, seriam periódicos não "dedicados ou vendidos ao servelismo". ${ }^{8}$ Mediante a exposição prévia de suas intenções, os jornais definiam um público subscritor específico, alinhado com as suas posições. No caso do Correio, parece que se buscava a adesão de leitores que se julgassem 'moderados' por se colocarem entre os extremos viciosos ocupados pelos simpáticos ao despotismo e pelos serviçais da ordem vigente. Teoricamente, podemos pensar a própria virtude como estando entre quaisquer vícios polares (Lausberg, 2011, p. 115).

É possível discernir os recursos persuasivos já nesse primeiro material do Correio, pois não há intenção de ocultar a persona jornalística com a retórica da objetividade e da neutralidade. O já citado Álvaro Klafke, autor de tese sobre "o discurso de construção de um Estado unificado", notou esse aspecto na imprensa periódica sul-rio-grandense entre 1831 e 1835 (Klafke, 2011, p. 37 38). No Prospecto, cada uma das finalidades do jornal ocupa um parágrafo; dos sete, três são introduzidos por verbos na primeira pessoa do plural: "Publicaremos", "Enunciaremos", "Apresentaremos"; os demais são destacados por "Banir-se-á", "Não prometemos" e "Aceitão-se”. Esses recursos, além dos argumentos lógicos e patéticos (se for possível realmente separar uns dos outros), auxiliam a constituir o éthos do jornal. Outra estratégia ética evidente é a autodepreciação do responsável pelo empreendimento, mitigada pelo uso da primeira pessoa do plural - trata-se da figura de pensamento denominada cleuasmo, importante para obtenção da boa vontade do leitor e para disfarçar um autoelogio. Esse recurso foi usado ao mesmo tempo que se amplificava, pela repetição, a postura política de "aversão aos Despotismos":

Não prometemos ao Leitor essa transcendente instrução, que se faz necessária a quem se dedica a instruir o público, por não ter cabido em partilha, hum espírito talentoso e suficientemente instruído nas materias de que pretendemos fallar; nós nos esforçaremos para mostrar quais são nossos desejos pelo bem de nossos Concidadãos, nosso zelo pela liberdade, e nossa aversão aos Despotismos, já dos grandes, já dos pequenos Mandões. (Correio da Liberdade, Prospecto)

A despeito da deficiente instrução, prometia-se "instrução" ao público (o "povo brasileiro", mesmo hoje, pode ser concebido como um ser carente de educação em todos os sentidos), luta pela liberdade e combate aos "despotismos" de todos os tamanhos. A autodepreciação seria ainda característica marcante do primeiro número do periódico: 
Eis-nos finalmente metendo hombros a trabalhosa e difícil empresa, a que nos proposemos, quando deliberamos redigir este Periodico; e bem que nossas forças não sejão similhante ás do membrudo Atlante, para que sem vergarmos, nos submetamos á immensa mole, que se nos apresenta; bem que não possamos competir em forças com o Alcides, para que nos seja permittido extinguir e desbaratar a ultima cabeça da Hydra Lernea, que nos ameaça, não esmoreceremos com tudo no audacioso propósito, confiando em os ardentes dezejos, que temos de ser prestadios a justa causa da nossa Patria, e uteis quando em nós couber, a nossos Concidadãos, supprirão a falta, que em nós reconhecemos, e não duvidamos confessar da necessaria instrucção. (Correio da Liberdade, n. 1, 17 abr. 1831)

O desejo de obter a simpatia do leitor implica o uso das estratégias buscando, por um lado, estimar como sobre-humanas as tarefas assumidas - a publicação e o enfrentamento de ameaça política (a "última cabeça da Hidra de Lerna"), somente passíveis de enfrentamento pela superior imposição do "desejo" patriótico. O recurso às comparações com figuras heroicas - Atlante e Alcides/Héracles - são, ao mesmo tempo, indicadoras de erudição contrastante com a manifesta afirmação de limitada instrução intelectual, estratégia mantida na sequência do texto:

O titulo, que tomamos, nos impõe obrigações sagradas, ainda que arduas sem duvida; empregaremos com tudo os maiores exforços, para que da maneira possível aspiremos ao seu glorioso desempenho, procurando satisfazer a todas as nossas promessas, senão com a pomposa eloquencia de hum Cicero, ou de hum Demosthenes, pelo menos com huma linguagem franca, e intelligivel para todos os nossos Leitores. Permitta o Ceo, que com ella e com as incontestaveis provas de nossos puros sentimentos possamos captar-lhes as benévolas attenções, e merecer a indulgencia de que tanto havemos mister. (Correio da Liberdade, n. 1, 17 abr. 1831)

O esforço em captar a benevolência pela expressa modéstia das qualidades dos responsáveis pelo jornal - que nunca estariam à altura de expoentes da antiga eloquência greco-romana - já estava, como vimos, na frase imediatamente anterior, que pedia o auxílio dos "Concidadãos" para suprir uma confessada falta de instrução. Essa manifesta limitação, porém, ofereceria a contrapartida de duas qualidades admiráveis: franqueza e inteligibilidade. A contrabalançar tal modéstia, a própria citação das autoridades, Cícero e Demóstenes, e o uso peculiar da expressão latina, captatio benevolentiae 
("possamos captar-lhes as benévolas atenções”), indicando ao leitor informado o conhecimento da clássica estratégia retórica latina.

\section{A RECEPÇÃO DA TIRANIA PISISTRÁtIDA PELO \\ CORREIO E SUA CADEIA DE RECEPÇÕES}

Gostaria de sublinhar agora: a dimensão retórica do discurso é uma das vias de articulação com a teoria da Estética da Recepção. Hans Robert Jauss, ao discorrer sobre o seu entendimento dos três conceitos da tradição estética - poíesis, aísthēsis e kátharsis - que interliga com as três categorias da fruição estética (produção, recepção e comunicação), define kátharsis como "aquele prazer dos afetos provocados pelo discurso ou pela poesia”, capaz de conduzir o ouvinte ou o espectador tanto "à libertação de sua psique" quanto, destaco, “à transformação de suas convicções” (Jauss, 2002, p. 100-101). A esse prazer específico caberia a função de transformar a experiência subjetiva em intersubjetiva pela anuência ao juízo exigido pela obra ou pela identificação com normas de ação predeterminadas e a serem explicitadas (Jauss, 2002, p. 102).

A ligação entre persuasão e prazer pode ser diretamente associada à prova retórica que pouca atenção recebe no campo da disciplina histórica, o páthos: "Persuade-se pela disposição dos ouvintes, quando estes são levados a sentir emoção por meio do discurso, pois os juízos que emitimos variam conforme sentimos tristeza ou alegria, amor ou ódio" (Aristóteles, Retórica, I, 1356 14-19).9

Devo confessar minha emoção ao ler, pela primeira vez, a matéria que segue. Estou acostumado a ler a respeito e a tratar de Pisístrato em sala de aula. Não me lembro de menção a tal importante personagem da história política ateniense em meio não profissional. Encontrar, portanto, essa matéria me causou considerável impacto, pois se trata de reflexão sobre a política brasileira na qual se usa como exemplo episódio da história antiga de conhecimento muitíssimo restrito nos dias de hoje. ${ }^{10}$ Reproduzo-a por completo para correta apreciação do leitor:

\section{DAS MONARCHIAS MODERADAS}

PISISTRATO fez respeitar as Leys dadas por Solon, e as respeitou elle mesmo. O Areopago continuou a ter o deposito dellas, e o Senado foi ainda, ou pelo menos pareceu ser o Conselho do Principe, como o havia sido da Republica. Não esteve no poder de Pisistrato governar arbitrariamente. Elle governou pelas Leys, porque se vio na necessidade de aproveitar o Areopago, e o Senado, que vellavão sobre a 
sua administração: dois Corpos tão temíveis, que o seu descontentamento teria sublevado todos os Cidadãos. Se na Democracia estes dois Corpos erão bastante fracos para equilibrar o poder do Povo reunido, vê-se que logo que o Governo passa a ser Monarchico, são assaz poderosos para equilibrar o poder do Monarcha. Ora esta Monarchia He hum exemplo das Monarchias, a que se dá o nome de moderadas. He nestas Monarchias, que verdadeiramente se He livre. A licença do povo tem hum freio nas Leys, que o Monarcha lhe faz respeitar, e a licença do Monarcha tem igualmente hum freio nas Leys, que o Areopago, e o Senado forção a respeitar elle mesmo. Os Cidadãos estão ao abrigo da anarchia, porque não $\mathrm{He} o$ Povo que se governa; estão também ao abrigo do despotismo, porque o Monarcha não governa com huma authoridade absoluta. Sua liberdade consiste em não ser sugeito, senão ás Leys, e tanto que este governo subsiste, póde dizer-se sem temor de fazer hum circulo vicioso, que as Leys regulão o uso do poder soberano. Nas Monarchias, taes como a de Athenas no tempo dos Pesisttatides, o Monarcha não póde tudo; elle póde o bem, mas não póde o mal. Não póde o mal, porque basta huma injuria feita a hum Cicadão para sublevar todo o povo, e o Tyranno está derrubado. Hipparque e Hippias são prova disto $\left({ }^{*}\right)$ Vós vedes que os Athenienses não se teriao considerado livres se o Monarcha tivesse podido offender impunemente hum só Cidadão. Ora esta opinião bastava para forçar a authoridade a conter-se nos lymites prescritos pelas Leys. Neste Governo o Areopago e o Senado não recebião a authoridade do Monarcha, mas sim das Leys fundamentaes dadas por Sólon; Leys a que Pisistrato era sugeito; Leys, que elle não podia mudar, porque erão protegidas por Corpos poderosos, e pela opinião, de que elle mesmo supportava o jogo. Nem todas as Monarchias Moderadas são constituídas como a de Athenas no tempo dos Pisistratides; e nós veremos muitas especies dellas. Este Governo por sua constituição He mesmo sugeito a variação continuas, por que os Poderes, que se contrabalanção, fazem continuamente esforços para ter cada hum a preponderancia. O Monarcha quer estender sua authoridade e limitar a dos Corpos, os Corpos querem estender a sua, e limitar a do Monarcha. Assim a balança pende alternativamente, ora de hum lado, ora de outro. Mas que He comum a todas as Monarchias Moderadas, e oque faz a natureza dellas, He ter Leys fundamentaes, que o Monarcha não tem o poder de mudar arbitrariamente.

Condillac.

$\left.{ }^{\star}\right)$ Para provar esta verdade não precizamos recorrer a exemplos tão remotos: infelizmente os nossos tempos tem sido fertis de similhantes catastrophes; e agora mesmo o acabamos de ver entre nós. (Correio da Liberdade, n. 9, p. 33-34, ${ }^{11} 14$ maio 1831) 
Considerando o que escrevi sobre a postura política do Correio, podemos entender a publicação dessa matéria já pela leitura de seu título: "Das Monarchias Moderadas". Contudo, no tocante à recepção da tirania pisistrátida como exemplo desse tipo de regime, não pode deixar de haver assombro. Da minha parte, pelo menos.

Quando afirmou que não se pode subordinar a recepção ao propósito de composição da obra, Hans Jauss (2002, p. 102) pretendia combater a tese da interpretação única, transcendentalmente correta; não era seu objetivo impedir o juízo dos leitores sobre as diversas interpretações feitas ao longo do tempo. A caracterização da tirania de Pisístrato como "monarquia moderada" e de Pisístrato como "príncipe" são incorretas; chamar o Conselho ateniense dos 500 de "Senado", idem. Entretanto, o uso de "República" para caracterizar Atenas pertence a uma tradição que lhe ultrapassa, pois assim eram chamadas Grécia e Roma nos textos do Humanismo e do Renascentismo e mesmo nos melhores estudos do início do século XIX. E a mesma matéria, com título, à primeira vista, absurdo, é recepção de uma tradição que remonta à Antiguidade, pois Heródoto foi o primeiro, entre alguns, a matizar a tirania de Pisístrato.

Dominick LaCapra escreveu: “O texto é considerado como o 'lugar' de intersecção da tradição prolongada e da época específica e produz variações em ambas. Mas não está imobilizado nem se apresenta em um mundo autônomo; ele está situado numa rede plenamente relacional" (LaCapra, 1988, p. 262-263, trad. minha). Em geral, pensamos o contexto como apenas o econômico, social, político, a mentalidade de um tempo; ele pode, contudo, também ser, como já indiquei, uma "cadeia de recepções", uma "tradição intelectual". ${ }^{12}$ LaCapra se referia a textos literários canônicos; creio, porém, ser isso aplicável ao modesto Correio da Liberdade. No caso do juízo sobre a tirania de Pisístrato, a tradição pode ser remontada a Heródoto, passa por Tucídides e Aristóteles e se prolonga pela Antiguidade.

Conforme Heródoto: "Bem nesse momento, Pisístrato governou os atenienses, não alterando os que eram magistrados nem mudando as leis, e sob essas circunstâncias estabelecidas, administrou a cidade, bela e ordenadamente bem" (Histórias, I 59-60). O comentário tucidideano é um elogio genérico da tirania de Pisístrato e da de seus filhos, Hípias e Hiparco. É feito depois de sua digressão sobre o assassinato do segundo em razão de uma trama amorosa:

Na realidade, ele [Hípias] não exercia sobre o povo poder opressivo, mas governava-o sem lhe provocar ressentimentos. Estes tiranos desempenharam seus cargos com máxima integridade e prudência e embora cobrassem aos Atenienses 
somente a vigésima parte dos seus ganhos, adornaram a cidade de forma primorosa, continuaram as suas guerras e ofereceram sacrifícios nos templos. Além disso, esta cidade continuou a usar as leis antes estabelecidas, mas eles tomaram o cuidado de ter sempre no poder um deles. (Guerra do Peloponeso, VI. 54, 5-6)

$\mathrm{Na}$ Constituição dos Atenienses, de Aristóteles, há outra observação atenuadora sobre a primeira tirania de Pisístrato: "obtido o poder, administrava os negócios públicos antes como cidadão do que como tirano" (Aristóteles, $A$ Constituição..., XIV, 5). E, posteriormente:

Pisístrato, como foi dito, administrava os negócios da cidade com moderação, e antes como cidadão do que como tirano. Em geral, com efeito, era humano, brando e clemente para com os infratores e, em particular, adiantava empréstimos em dinheiro aos que estavam em dificuldades, viabilizando seus trabalhos de modo a se sustentarem com os cultivos das terras. [...] Em geral, durante o seu governo não atormentou a multidão em nada, antes sempre manteve a paz e velou pela tranquilidade; e por isso mesmo, difundira-se a fama de que a tirania de Pisístrato era como a vida no tempo de Cronos - com efeito, o poder se tornou bem mais severo mais tarde, quando seus filhos o sucederam. (Aristóteles, $A$ Constituição..., XVI, 2, 7-9)

Minha intenção não é, neste momento, contrastar de forma detalhada os fragmentos mais antigos dessa tradição com a matéria do jornal, nem tampouco analisar esta última a fundo. Creio ser mais pertinente, para os propósitos do artigo, destacar a rede de apropriações da Antiguidade à qual "Das monarchias moderadas" pertence, pois houve uma retomada do tópos tirania a partir do Humanismo, a qual continuou durante a Renascença e o Iluminismo, particularmente no tocante à teoria política (Goff; Leonard, 2016, p. 1). Essa recepção persistiu no século XIX, inclusive no Brasil: a partir de uma matização qualificadora da tirania pisistrátida, a matéria do Correio extrapolou para uma teoria da monarquia constitucional, manipulando os elementos daquelas informações provenientes de um longínquo passado, houvesse conhecimento direto disso ou não.

Há evidência de que o conhecimento fosse indireto, pois a assinatura ao final do artigo é de "Condillac". Étienne Bonnot de Condillac, abade de $\mathrm{Mu}$ reau (1715-1780), foi um filósofo iluminista francês, defensor de uma teoria do conhecimento empirista e sensualista, apropriada pelos Ideólogos franceses (Rüegg, 2004, p. 545), mas igualmente escritor de uma obra como Le Commerce et le gouvernement considérés relativement l'un à l'autre (1776). Não foi um 
dos grandes filósofos das Luzes e é, segundo um de seus estudiosos brasileiros, objeto de menor atenção pelos estudos filosóficos contemporâneos (Silva, 2013, p. 270; Silva, 2016, p. 20-21). No Brasil recente, a versão de sua obra capital, Ensaio sobre a origem dos conhecimentos humanos (1714), foi publicada em 2018. Desfrutou, entretanto, de considerável prestígio em seu tempo e posteriormente, como em Portugal e no Brasil do século XIX. Condillac escreveu importantes trabalhos no campo da epistemologia, como o mencionado Ensaio (divulgador do pensamento de Locke entre os franceses) e principalmente o Traité des sensations (1754), tendo sido admitido à Academia Francesa em 1768. Contemporaneamente a nós, foi objeto da atenção de Derrida (em “A arqueologia do frívolo", Derrida, 1973) e de Michel Foucault (em As palavras e as coisas, Foucault, [1966]2000). Foi graças à necessidade de compreender a recepção de Condillac pelo Correio da Liberdade que descobri ter Foucault invocado reiteradamente o Abade para responder à pergunta: "sob que condições o pensamento clássico pôde refletir, entre as coisas, relações de similaridade ou de equivalência que fundam e justificam as palavras, as classificações, as trocas?” (Foucault, 2000, p. XX).

A busca na plataforma da Hemeroteca Digital da Biblioteca Nacional brasileira proporcionou resultados ainda mais importantes. Em primeiro lugar, encontrei a mesma matéria sobre as "monarquias moderadas" publicada pelo jornal carioca Astréa em 16 de fevereiro de 1832, na quarta e quinta páginas do número 799. Além disso, há 33 ocorrências em 129 acervos de periódicos entre 1820 e 1829, e 109 ocorrências em 364 acervos entre 1830 e 1839. Há matérias como a de outro jornal de meu estado - em O Noticiador, de 5 out. 1831 ( $\mathrm{n}^{\circ}$ 50, p. 200): uma pequena nota sobre os efeitos da paz e da guerra sobre os homens - e diversas propagandas da venda de obras do Abade. São desse gênero as quatro ocorrências encontradas no Diário do Rio de Janeiro, jornal criado pelo português Zeferino Vito Meirelles em 1821. Em 27 de julho de 1822 (n²3, p. 92), por exemplo, noticiava-se a venda das Oeuvres de Condillac, em 31 volumes, na Loja de Francisco Saturnino Veiga, Rua da Alfândega, 395.

O mais relevante, porém, foi a descoberta de que essa matéria, publicada no Rio Grande do Sul e no Rio de Janeiro, é tradução das palavras de Étienne Bonnot, do capítulo VI do Tomo Oitavo de suas Oeuvres Complètes, relativa à Histoire Ancienne, cujo título é Des monarchies moderées. É parte de um Cours d'études de 13 volumes, datados de 1775 e escritos para o jovem duque, e neto de Luís XV, Ferdinand de Parme, de quem foi professor de 1757 a 1769. A obra inclui Grammaire, Art d'écrire, Art de raisonner, Art de penser et Histoire, e, logo no parágrafo inicial do primeiro volume consagrado a Histoire Ancienne, 
o autor adverte ser seu objetivo apenas ensinar o príncipe a estudar história, limitando-se a lições elementares, não tendo, como um historiador teria, "o objetivo de entrar em todos os detalhes que mereceriam ser conhecidos." (Condillac, 1821-1822, p. 1). O quarto livro é dividido em três partes independentes: os jogos na Grécia, o povo judeu e as leis, e a tirania de Pisístrato comparece nesta última parte como exemplo de "monarquia moderada" (p. 76-88). Reproduzo apenas a abertura do capítulo que, tal como a notícia em português, começa assim:

\section{CHAPITRE VI.}

Des monarchies modérées.

Pisistrate fit respecter les lois données par Solon, et les respecta lui-même. Laréopage continua d'en avoir le dépôt, et le sénat fut encore, ou du moins parut être le conseil du prince, comme il l'avait été de la république. (Condillac, $1821-1822$, p. 76$)^{13}$

As matérias do Correio e da Astréa são traduções desse capítulo de Histoire Ancienne. A reproduzida pelo jornal gaúcho tem, contudo, particularidades: está nas duas primeiras páginas, apresenta um título em maiúsculas, Pisístrato, a destacar o texto, e uma curiosa nota de rodapé indicada por asterisco. Trata-se de comentário inserido pelo redator do jornal: "Para provar esta verdade não precizamos recorrer a exemplos tão remotos: infelizmente os nossos tempos tem sido fertis de similhantes catastrophes; e agora mesmo o acabamos de ver entre nós”. A observação pessoal de Calcas parece ser referência direta à abdicação de Pedro I, ocorrida em 7 de abril de 1831, porque a "verdade" é referência sem maiores explicações a Hípias e a Hiparco, um exemplo do que pode acontecer quando um tirano não respeita as leis.

Hípias e Hiparco foram filhos de Pisístrato, e o primeiro sucedeu o pai como tirano. Tucídides criticou os atenienses por consagrarem ambos como heróis da luta contra a tirania, e ofereceu sua versão dos fatos. Hiparco teria assediado sexualmente Harmódio, "um belo jovem na flor da idade"; por isso, foi assassinado pela vítima e por seu amante, Aristogíton, "cidadão ateniense de meia idade" (Guerra do Peloponeso, VI, 54, 2). A tirania, sabemos, foi derrubada por um movimento liderado pelo futuro tirano Clístenes, com apoio essencial dos espartanos (Condilo, 2007, p. 3). Aristóteles considerou a história amorosa uma invenção dos partidários da democracia, a fim de denegrir a tirania de Hípias (Constituição dos Atenienses, 18.3.3). De qualquer forma, 
Aristogíton e Harmódio já tinham uma estátua que os consagrava como "Os Tiranicidas" quando ocorreu a segunda invasão persa (480 a.C.). Foi tomada por Xerxes como espólio de guerra e devolvida aos atenienses por Alexandre (Lefèvre, 2013, p. 143-155).

Esse comentário em nota de pé de página é um sinal impressionante de como seus autores sabiam - e supunham que seus leitores conheciam - a história política ateniense. Quem sabe algo sobre Hípias e Hiparco em nossos dias? Para entender a nota que conclui o artigo é necessário conhecer a história tradicional e antiga dos "Tiranicidas"; apenas assim é possível inferir que um monarca estava sujeito a ser deposto, e mesmo a ser assassinado, caso atacasse um cidadão. Pedro I, sabemos, abdicou.

Há outros indícios de que a tirania grega foi invocada para pensar os acontecimentos do início da história do Brasil independente. Na mesma época, o tirano grego também foi objeto de rápido comentário de O Correio Braziliense, o primeiro jornal brasileiro. Em dois números do ano de 1819 foi publicado o longo discurso de Simón Bolívar, quando da instalação do Congresso Geral da Venezuela. Defendendo o "Governo Republicano", instou os ouvintes a usarem a história como guia para evitar o perigo da "democracia absoluta":

Sirvanos a historia de guia nesta carreira. Athenas he a primeira, que nos da o exemplo mais brilhante de uma democracia absoluta, e logo a mesma Athenas nos offerece o exemplo mais triste da extrema debilidade desta espécie de Governo. O mais sábio legislador da Grécia naõ vio conservar a sua Republica dez annos, e soffreo a humiliaçaõ de reconhecer a insufficiencia da Democracia absoluta, para reger nenhuma espécie de sociedade, nem ainda a mais culta, morigerada e limitada; porque só brilha com relâmpagos de liberdade. Reconheçamos pois que Solon tem desenganado o mundo; e lhe tem ensinado, quam difficil he dirigir por simples leys aos homens. (Correio Braziliense, out. 1819)

Os leitores precisaram esperar o mês seguinte para concluir a leitura do discurso, o qual continuou assim:

A republica de Esparta, que parecia uma invenção chimerica, produzio mais effeitos reaes do que a obra engenhosa de Solon. Gloria, virtude, moral, e por conseguinte a felicidade nacional, foi o resultado da legislação de Licurgo. Ainda que dous reys em um Estado, são dous monstros para o devorar, Esparta teve pouco que sentir de seu duplicado throno: no entanto que Athenas se promettia a sorte mais esplendida, com uma soberania absoluta, livre eleição de seus magistrados, freqüentemente renovados, leys suaves, sábias e politicas. Pisistrato, usur- 
pador e tyranno, foi mais saudável a Athenas, do que as suas leys, e Pericles, ainda que também usurpador, foi o mais útil cidadão. (Correio Braziliense, nov. 1819)

Em o Correio da Liberdade, o elogio de Pisístrato era pela sua submissão às leis; no discurso de Bolívar, o elogio do "usurpador" é decorrência da crítica à democracia "absoluta" instituída por Sólon (c. 638-c. 558 a.C.). Este e Licurgo (c. IX a.C.) foram "legisladores", o nome dado a reformadores das póleis pela via legal. Sólon precedeu a Pisístrato e tentou estabelecer uma "boa ordem" (eudaimonia), contando com a disposição para o entendimento das partes envolvidas (Dabdab Trabulsi, 2001, p. 62). O fracasso de sua reforma resultou nas tiranias pisistrátidas. Não pensamos hoje ter Sólon instituído uma democracia, mas, no final do século IV a.C., os atenienses democratas o consideravam herói fundador do regime isonômico. ${ }^{14}$ Ainda no discurso de Simón Bolívar, é curiosa a qualificação de Péricles como "usurpador”. Péricles foi líder mediante o exercício de uma relevante magistratura, para a qual se elegeu sucessivas vezes. Provavelmente, o juízo do líder latino-americano é resultado de peculiar interpretação da avaliação tucidideana, segundo a qual Atenas era uma democracia apenas no nome, pois era governada por apenas um único homem, o seu "cidadão mais importante”, o alcmeônida Péricles (Guerra do Peloponeso, II. 65, 9).

Encontrei outros materiais em que Pisístrato, para minha surpresa, é personagem da reflexão política cotidiana de brasileiros do início do século XIX. ${ }^{15}$ Não eram muitos os capazes desse tipo de invocação do Mundo Antigo, tendo em vista o limitado alcance da formação intelectual da época. No entanto, são evidências do vital sentido da recepção da Antiguidade naqueles tempos, de uma forma hoje não mais possível. Quem, em nossa época, pensaria em Pisístrato para tratar do futuro político brasileiro? ${ }^{16}$

A situação era diferente há dois séculos.

Estando certa a tese de que os exemplos permitem fundamentar uma regra, passando de um caso particular a outro (Perelman; Olbrechts-Tyteca, 2005, p. 412), então o exemplo histórico implica aceitar uma comunhão essencial entre as épocas. A imprensa fornece uma evidência importante porque pode ser considerada como um valioso meio de avaliação da vitalidade de uma obra. Na interpretação de Mikhail Bakhtin, ela é a forma superior da "ideologia do cotidiano": a totalidade da atividade mental do indivíduo centrada sobre a vida cotidiana e a expressão a ela ligada (Bakhtin, [1929]1990, p. 118-120). É uma de suas formas superiores por estar em contato com os sistemas ideológicos - a ciência, a moral, o direito, a história. Esses, por um lado, 
cristalizam-se a partir da "ideologia do cotidiano" e, por outro, exercem uma forte influência sobre esta última. A sobrevivência dos sistemas ideológicos depende da manutenção desse vínculo, pois é na reflexão dos indivíduos sobre a sua vida diária que se realiza a avaliação crítica desses sistemas, de sua capacidade de serem significativos para determinado grupo, em determinado momento. A recepção da Antiguidade pela imprensa gaúcha e brasileira do século XIX é evidência de seus relevantes argumentos na reflexão sobre a vida cotidiana e política daquela época.

\section{FONTES}

\section{Arquivísticas}

CORREIO DA LIBERDADE, Porto Alegre, 14 de maio de 1831. Museu da Comunicação Hipólito José da Costa, Porto Alegre.

CORREIO BRAZILIENSE. [Hipólito José da Costa], Londres, Impresso por W. Lewis, (1808-1822). Disponível na Biblioteca Brasiliana Guita e José Midlin: https://www. bbm.usp.br/pt-br/. Acesso em: 1 mar. 2020.

ASTRÉA. Rio de Janeiro, 16 fev. 1832. Hemeroteca Digital da Biblioteca Nacional Digital. Disponível em: http://bndigital.bn.gov.br/hemeroteca-digital/. Acesso em: 1 mar. 2020.

O NOTICIADOR, Porto Alegre, 5 out. 1831; 24 jan. 1832; 13 set. 1832.

ANAIS DO IMPÉRIO (digitalizados). Disponíveis em: https://www.senado.leg.br/publicacoes/anais/asp/IP_AnaisImperio_digitalizados.asp. Acesso em: 10 maio 2020.

RIO GRANDE DO SUL (Estado). Lei no 5213, de 5 de janeiro de 1966. Dispõe sobre a forma e a apresentação dos símbolos do Estado do Rio Grande do Sul e dá outras providências. Disponível em: https://leisestaduais.com.br/rs/lei-ordinaria-n-5213-1966-rio-grande-do-sul-dispoe-sobre-a-forma-e-a-apresentacao-dos-simbolos-do-estado-do-rio-grande-do-sul-e-da-outras-providencias. Acesso em: 1 mar. 2020 .

\section{Textuais}

ARISTÓTELES. A Constituição de Atenas. Tradução e comentários de Francisco M. Pires. São Paulo: Hucitec, 1995.

ARISTÓTELES. Retórica. Tradução de Manuel Alexandre Júnior, Paulo Farmhouse Alberto e Abel do Nascimento Pena. São Paulo: Martins Fontes, 2012.

CAIRÚ, José da Silva Lisboa, Visconde de. Estudos do Bem-Commum e Economia Politica, ou sciencia das leis naturaes e civis de animar e dirigir a geral industria, $e$ 
promover a riqueza nacional, e prosperidade do estado (Parte 3 Seção 2). Rio de Janeiro: Imprensa Régia, 1820.

CÍCERO, Marco Túlio. Dos deveres. Tradução de Angélica Chiapetta. Revisão da tradução de Gilson Cezar Cardozo de Souza. São Paulo: Martins Fontes, 1999.

CONDILLAC, Étienne Bonnot de. Oeuvres complètes de Condillac. Tome VIII. Paris: Lecointe et Durey, 1821-1822.

GÓRGIAS. Tratado do não-ente. Elogio de Helena. Tradução de Maria Cecília de Miranda N. Coelho. Cadernos de tradução, São Paulo: DF/USP, n. 4, p. 11-28, 1999. HERÓDOTO. Histórias. Livro I. Clio. Tradução de Maria Aparecida de Oliveira Silva. São Paulo: Edipro, 2015.

HOMERO. Ilíada. Tradução e prefácio de Frederico Lourenço. São Paulo: Companhia das Letras, 2013.

ISOCRATES. Areopagiticus. In: ISOCRATES, vol. II. Translated by George Norlin. London: William Heinemann, 1929. (Loeb Classical Library, No. 229).

QUINTILIANO. Instituição Oratória. Tomos II, IV, V e VI. Tradução, apresentação e notas de Bruno Fregni Basseto. Campinas: Ed. Unicamp, 2015.

TUCÍDIDES. História da Guerra do Peloponeso. 2. ed. Tradução, prefácio e notas introdutórias de Raul M. Rosado Fernandes e M. Gabriela P. Granwehr. Lisboa: Calouste Gulbenkian, 2013.

\section{REFERÊNCIAS}

ABREU, Rafael Santos de. "Sejamos gregos na glória / e na virtude, romanos": os usos da Antiguidade clássica na imprensa periódica sul-rio-grandense no discurso de construção da Nação em O Correio da Liberdade e O Noticiador (1831-1835). 2014. Trabalho de Conclusão de Curso - Departamento de História, UFRGS. Porto Alegre, 2014.

BAKHTIN, Mikhail. Marxismo e filosofia da linguagem. [1929]. São Paulo: Hucitec, 1990.

BAUMGARTEM, Carlos Alexandre. Literatura e crítica na imprensa do Rio Grande do Sul - 1868 a 1880. Porto Alegre: Escola Superior de Teologia São Lourenço de Brindes, 1982.

CARVALHO, José Murilo de. As conferências radicais do Rio de Janeiro: novo espaço de debate. In: CARVALHO, José Murilo de (org.). Nação e cidadania no Império: novos horizontes. Rio de Janeiro: Civilização Brasileira, 2007.

CARVALHO, José Murilo de. História intelectual no Brasil: a retórica como chave de leitura. Topoi - Revista de História, Rio de Janeiro: 7 Letras, n. 1, p. 123-152, 2000.

CONDILO, Camila da Silva. O papel dos tiranicidas na constituição da identidade democrática em Atenas. Classica, Belo Horizonte, v. 20, n. 1, p. 78-92, 2007. 
COSTA, Letícia. Você sabia que um trecho do Hino Rio-Grandense foi excluído? Portal G1. 2015. Disponível em: http://g1.globo.com/rs/rio-grande-do-sul/semana-farroupilha/2015/noticia/2015/09/voce-sabia-que-um-trecho-do-hino-rio-grandense-foi-excluido.html. Acesso em: 1. mar. 2020.

DABDAB TRABULSI, José Antonio. Ensaio sobre a mobilização política na Grécia Antiga. Brasília: Ed. UnB, 2001.

DERRIDA, Jacques. L'archéologie du frivole, Lire Condillac. Paris: Galilée, 1973.

DURAN, Maria Renata da C. Retórica à moda brasileira: transições da cultura oral para a cultura escrita no ensino fluminense de 1746 a 1834. São Paulo: Ed. Unesp, 2013. Disponível em: http://editoraunesp.com.br/catalogo/9788539304790,retorica-a-moda-brasileira. Acesso em: 5 jan. 2017.

ELMIR, Cláudio Pereira. Uma aventura com o Última Hora. O jornal e a pesquisa histórica. Anos 90, Porto Alegre: UFRGS, v. 19, n. 36, p. 67-90, dez. 2012. Disponível em: https://seer.ufrgs.br/anos90/article/view/31063. Acesso em: 10 fev. 2017.

FERREIRA, Márcio M. C. "Bacantes" e duas cenas de mensageiro na tragédia grega (parte 2). O Estado de S. Paulo, São Paulo, 26 jul. 2019. Estado da Arte. Revista de Cultura, Artes e Ideias. Disponível em: https://estadodaarte.estadao.com.br/bacantes-e-duas-cenas-de-mensageiro-na-tragedia-grega-parte-2/. Acesso em: 10 maio 2020.

FRANCO, Maria Sylvia C. A engrenagem da dominação. Folha de S. Paulo, São Paulo, 28 abr. 2002. Caderno “Mais!”. Disponível em: https://wwwl.folha.uol.com.br/fsp/ mais/fs2804200206.htm. Acesso em: 10 maio 2020.

FOUCAULT, Michel. A palavra e as coisas: uma arqueologia das ciências humanas. [1966]. 8. ed. São Paulo: Martins Fontes, 2000.

GADAMER, Hans-Georg. Verdade e método. 3. ed. Tradução de Flávio Paulo Meurer. Petrópolis: Vozes, 1999.

GOFF, Barbara; LEONARD, Miriam. Introduction: The Legacy of Greek Political Thought. Classical Receptions Journal, London, v. 8, n. 1, p. 1-10, 2016.

HARDWICK, Lorna. Reception studies. Oxford: Oxford University Press, 2003.

HORNBLOWER, Simon. The greek world. 479-323. [1983]. Revised edition. London: Routledge, 1991.

JAUSS, Hans Robert. O prazer estético e as experiências fundamentais da poiesis, aisthesis e katharsis. In: LIMA, Luiz Costa. A literatura e o leitor: Textos de estética da recepção. [1979]. 2. ed. revista e ampliada. Rio de Janeiro: Paz e Terra, 2002.

KLAFKE, Álvaro A. Antecipar essa idade de paz, esse império do bem: imprensa periódica e discurso de construção do Estado unificado (São Pedro do Rio Grande do Sul, 1831-1845). 2011. Tese (Doutorado em História) - Universidade Federal do Rio Grande do Sul (UFRGS). Porto Alegre, 2011. 
LACAPRA, Dominick. Repensar la historia intelectual y leer textos. In: PALTI, Elías José. Giro Linguístico e História Intelectual. Quilmes: Universidad Nacional de Quilmes, 1988.

LACAPRA, Dominick. Retórica e História. Revista Territórios \& Fronteiras, Cuiabá, v. 6, n. 1, p. 97-118, jan./jun. 2013.

LACAPRA, Dominick. Rhetoric and History. [1985]. In: LACAPRA, Dominick. History \& Criticism. New York: Cornell University Press, 1996. p. 15-44.

LAUSBERG, Heinrich. Elementos de retórica literária. [1967]. 6. ed. Lisboa: Calouste Gulbenkian, 2011.

LEFÈVRE, François. História do Mundo Grego. [2007]. São Paulo: Martins Fontes, 2013.

LUSTOSA, Isabel. Insultos impressos: a guerra dos jornalistas na Independência (18211823). São Paulo: Companhia das Letras, 2000.

MAINGUENEAU, Dominique. A propósito do éthos. In: MOTTA, Ana Raquel; SALGADO, Luciana (org.). Éthos discursivo. São Paulo: Contexto, 2008. p. 11-29.

MARTINDALE, Charles. Reception. In: KALLENDORF, Craig W. (ed.). A Companion to the Classical Tradition. Oxford: Blackwell, 2007. p. 297-311.

MARTINDALE, Charles. Redeeming the text: Latin poetry and the hermeneutics of reception. Cambridge: Cambridge University Press, 1993.

NEWELL, Waller R. Tiranos: uma história de poder, injustiça e terror. [2016]. São Paulo: Cultrix, 2019.

PARA mitologia, Atenas deve sua unidade a Teseu. Folha de S. Paulo, São Paulo, 10 mar. 2003. Turismo. Disponível em: https://wwwl.folha.uol.com.br/folha/turismo/ noticias/ult338u2429.shtml. Acesso em: 10 maio 2020.

PENNA, Fernando de A. A importância da tradição clássica no nascimento da disciplina História no Imperial Colégio de Pedro II. In: CHEVITARESE, André et al. (org.). A Tradição Clássica e o Brasil. Brasília: Fortium, 2008.

PERELMAN, Chaim; OLBRECHTS-TYTECA. Lucie. Tratado de argumentação: a nova retórica. [1958]. São Paulo: Martins Fontes, 2005.

RANCIĖRE, Jacques. Um profeta equívoco. Folha de S. Paulo, São Paulo, 31 jul. 2005. Caderno "Mais!". Disponível em: https:/www1.folha.uol.com.br/fsp/mais/ fs3107200507.htm. Acesso em: 10 maio 2020.

REBOUL, Olivier. Introdução à retórica. [1991]. São Paulo: Martins Fontes, 1998.

RÜDIGER, Francisco Ricardo. Linhagens do jornalismo gaúcho. Porto Alegre: [s.n.], 1990. (Reprografado).

RÜEGG, Walter. A History of the University in Europe. V. III. Universities the Nineteenth and Early Twentieth Centuries (1800-1945). Cambridge: Cambridge University Press, 2004.

SILVA, Lourenço F. N. e. A concepção de educação de Condillac. In: SEMINÁRIO DOS ESTUDANTES DA PÓS-GRADUAÇÃO EM FILOSOFIA DA UFSCar, 9., 
2013, São Carlos. Anais... São Carlos: Ed. UFSCar, 2013. p. 270-277. Disponível em: http://www.ufscar.br/ semppgfil/2013-2/. Acesso em: 27 set. 2019.

SILVA, Lourenço F. N. e. O animal em Condillac ou as reinvenções do humano. 2015. Dissertação (Mestrado em Filosofia) - Faculdade de Filosofia, Letras e Ciências Humanas, Universidade de São Paulo. São Paulo, 2016.

SOUZA, Roberto Acízelo de. O império da eloquência. Rio de Janeiro: Eduerj: Eduff, 1999.

A VERDADE sobre o trecho do hino gaúcho que os deputados cortaram há 50 anos. GZH. 2015. Disponível em: https://gauchazh.clicrbs.com.br/geral/semana-farroupilha/noticia/2015/09/a-verdade-sobre-o-trecho-do-hino-gaucho-que-os-deputados-cortaram-ha-50-anos-4842810.html. Acesso em: 10 maio 2020.

\section{NOTAS}

${ }^{1}$ Salvo observação em contrário, são meus os destaques nas citações.

${ }^{2}$ Um documentário da rede RBS desmente esta hipótese (ver: A VERDADE..., 2015).

${ }^{3}$ Inicialmente, tirano não era termo preciso nem era dotado de conotação negativa. Podia ser sinônimo de basileús, rei (VIAL, 2013, p. 304-305) e os tiranos da Sicília clássica (V século a.C.) mais se assemelharam a reis helenísticos, por política e comportamento (HORNBLOWER, 1991, p. 48). A tirania podia ser consideravelmente popular, caso se colocasse contra parte da aristocracia proprietária e se apoiasse no démos. Essa palavra do grego antigo é comparável a "povo" pelo que tem de imprecisa (pode abranger todos, a maioria, ou parcela dos cidadãos) e pela ambivalência conotativa: dependendo do interesse de seu usuário, podia ser usada positiva ou negativamente.

${ }^{4}$ A passagem completa: "Portanto, deve haver em todos o propósito único de fazer com que o interesse de cada um coincida com o interesse geral: pois se alguém o reservar só para si, provocará a dissolução do consórcio humano" (CÍCERO, 1999).

${ }^{5}$ A noção aristotélica destinava-se a discursos orais. Em relação aos textos escritos, podemos considerar as contribuições de Dominique Maingueneau:

> o êthos é uma noção discursiva, ele se constrói através do discurso, não é uma "imagem" do locutor exterior a sua fala;

$>$ o éthos é fundamentalmente um processo interativo de influência sobre o outro;

$>$ é uma noção fundamentalmente híbrida (sociodiscursiva), um comportamento socialmente avaliado, que não pode ser apreendido fora de uma situação de comunicação precisa, integrada ela mesma numa determinada conjuntura sócio-histórica (MAINGUENEAU, 2008, p. 17).

${ }^{6}$ Como se pode notar, manteve-se a redação original dos documentos.

${ }^{7}$ Destaque no original. 
${ }^{8}$ Prospecto de lançamento do Correio da Liberdade, Porto Alegre, [s. d., provavelmente abr. 1831]. A estimativa da data é de Álvaro Klafke (2011, p. 37).

${ }^{9}$ Pelo menos nesse texto, Jauss não relaciona seu conceito de kátharsis com a retórica aristotélica, mas com esta passagem de Górgias: "Os encantamentos inspirados divinamente, por meio das palavras, movem o prazer, removem a dor; conformando-se com a opinião da alma, o poder do encantamento a seduz, persuade e transforma essa alma pelo enfeitiçamento. De enfeitiçamento e magia duas técnicas se encontraram, que são erros da alma e ilusões da opinião" (GÓRGIAS, Elogio de Helena, 10).

${ }^{10}$ Hoje, depois de pesquisa em jornais nacionais e portugueses, meu espanto diminuiu consideravelmente a cada achado que faço. Em O Noticiador, da cidade gaúcha de Rio Grande, por exemplo, encontrei uma paráfrase da obra de Tucídides na edição de 24 jan. 1832, usada para criticar os jornais que estimulariam um clima de sedição no país. Uma paráfrase equivocada ao atribuir a descrição tucidideana da stásis (guerra civil) a Atenas e não, como é, a Corcira (Guerra do Peloponeso, III. 59-83). Além dessa matéria, há diversas outras a exaltar uma imaginada República Romana oligárquica, dita dos "virtuosos Dictadores" em artigo de 13 set. 1832. Esta é a característica distintiva dessas recepções do Mundo Antigo: não se restringem a temas canônicos de nosso tempo, como a decadência romana ou a democracia grega. São invocações argumentativas que revelam um conhecimento mais meticuloso daquele passado e que são usadas para pensar o tempo presente e vislumbrar o futuro.

${ }^{11}$ Os periódicos eram numerados sequencialmente e muitas vezes encadernados como livros ao final. A matéria, contudo, ocupou as duas primeiras páginas do Correio.

${ }^{12}$ Penso "tradição" conforme o entendimento de Martindale (2007, p. 300): algo constituído pelas apropriações de cada tempo e não como realidade independente da ação dos indivíduos a agir sobre todos.

${ }^{13} \mathrm{O}$ livro está disponível no Google Books. Há duas versões digitalizadas - em uma delas, falta uma das páginas da seção sobre Pisístrato. A referência da versão completa está na bibliografia.

${ }^{14}$ Para Isócrates (436-338 a.C.), a democracia fora instituída por Sólon e restabelecida por Clístenes (ISOCRATES, Aeropagiticus, 16).

${ }^{15}$ Como na obra de Visconde de Cairu listada na bibliografia (CAIRÚ, 1820) e também em discursos pronunciados no Senado imperial brasileiro. Confira o levantamento em: http:// www6g.senado.leg.br/busca/?portal=Publica\%C3\%A7\%C3\%A3o+e+Documenta\%C3\%A7 \%C3\%A3o\&q=Pis\%C3\%ADstrato. Acesso em: 10 maio 2020.

${ }^{16}$ Pesquisas nos principais jornais brasileiros contemporâneos resultaram nos seguintes números para citações de "Pisístrato": 3 menções na Folha de S. Paulo; 1 no Estado de S. Paulo e zero em O Globo. Na Folha, dois artigos de acadêmicos no antigo caderno "MAIS!": de Jacques Rancière comemorando o centenário do nascimento de Tocqueville (RANCIÈRE, 2005); de Maria Sylvia Carvalho Franco sobre a biografia de Júlio César escrita por Luciano Canfora (FRANCO, 2002). Há ainda uma nota sobre mitologia grega em 
2003, um ano antes da última Olimpíada em Atenas (PARA mitologia..., 2003). No Estadão, encontrei um artigo sobre as Bacantes, de Eurípedes, escrito por Márcio Mauá Chaves Ferreira, à época doutorando em Letras Clássicas pela USP (FERREIRA, 2019). Recentemente, editou-se um livro sobre tiranias em que Pisístrato está presente na introdução (NEWELL, 2019, p. 55, 60, 64, 74). A obra, conforme chamada da capa, seria leitura obrigatória "a todos com sério interesse em ciência política".

Artigo recebido em 3 de março de 2020. Aprovado em 25 de maio de 2020. 